\title{
Doppler Ultrasound of Hepatic and System Hemodynamics in Patients with Alcoholic Liver Cirrhosis
}

Drazen Zekanovic $\cdot$ Neven Ljubicic $\cdot$ Marko Boban •

Marko Nikolic · Diana Delic-Brkljacic · Petar Gacina •

Ivo Klarin · Jadranko Turcinov

Published online: 27 March 2009

(C) Springer Science+Business Media, LLC 2009

\section{Erratum to: Dig Dis Sci}

\section{DOI 10.1007/s10620-009-0760-1}

This article was published with the given name and family name for each of the eight authors in reverse order. The correct order, given name followed by family name, is shown in this erratum.

The online version of the original article can be found under doi: 10.1007/s10620-009-0760-1.

D. Zekanovic · M. Nikolic · D. Delic-Brkljacic · P. Gacina

I. Klarin · J. Turcinov

Department of Internal Medicine, County Hospital Zadar, Zadar,

Croatia

N. Ljubicic · M. Boban ( $₫) \cdot$ M. Nikolic · D. Delic-Brkljacic ·

P. Gacina

Internal Medicine Clinic, University Hospital "Sestre

Milosrdnice", Vinogradska Street 29, Zagreb, Croatia

e-mail: marcoboban@yahoo.com

URL: www.kbsm.hr 